\title{
Postioplastia modificada para a redução de fimose em cães
}

\author{
Modified posthioplasty to phimosis reduction in dogs \\ Luciano André Weide ${ }^{1}$, Emerson Antonio Contesini ${ }^{2}$, Marcio Poletto Ferreira ${ }^{1} \&$ Rafael Stedile $^{1}$
}

\begin{abstract}
RESUMO
A fimose em cães é uma afecção pouco freqüente em clínicas e hospitais veterinários. Porém, provoca muito desconforto ao animal afetado. Ela pode ser de origem adquirida, gerada por trauma, congênita ou por neoplasia, gerando inabilidade de exposição do pênis em relação ao prepúcio, causando postite, impossibilidade de copular, retenção de urina e dor. A complicação mais comum da fimose é a balanopostite, sendo que proprietário relata a dificuldade de miç̧ão e até mesmo disúria. O tratamento da fimose depende da sua origem, podendo ser clínico ou cirúrgico. O tratamento clínico baseia-se em medicações e compressas locais mornas, enquanto que para o tratamento cirúrgico indica-se a postioplastia. O objetivo do trabalho é demonstrar que a postioplastia modificada é de simples execução e traz menores problemas pós-operatórios. As cirurgias foram realizadas em dois cães de raças distintas, atendidos no Hospital de Clínicas Veterinárias do Rio Grande do sul (HCV-UFRGS). A técnica cirúrgica aqui descrita é uma modificação de duas técnicas já relatadas, proporcionando uma solução fácil e eficaz para o problema. Os resultados alcançados foram excelentes, comprovando a eficácia da cirurgia.
\end{abstract}

Descritores: prepúcio, pênis, fimose, cão.

\section{ABSTRACT}

The phimosis in dogs is not a very frequent affection in hospitals and veterinary clinics. However, bring about very discomfort to the affected animal. The phimosis can be acquired, congenital, traumatical or neoplasic generated, breeding a inability to expose the penis, causing postitis, crossing inability and pain. The most common complication of the phimosis is the balanophosthitis, and the owner relate that your animal have some difficulty to urine. The treatment of the phimosis depend of your cause, and can be clinical or surgical. The clinical treatment is based in medications and local warm compress, while to the surgical treatment is indicated the posthioplasty realization. The objective of this work is demonstrate that the modified posthioplasty have a simple execution and bring smallers problems after the surgery. The surgerys was realizated in two dogs of different races, attended in the Hospital de Clínicas Veterinárias do Rio Garnde do Sul (HCV-UFRGS). The surgical technics here described is a change of two another technics, propotioning an easy and quick solution to the problem. The obtained results was very excellents, confirming the efficacy of the surgery.

Key words: preputial, penis, phimosis, dog. 


\section{INTRODUÇÃO}

Fimose é a inabilidade de exposição do pênis a partir da bainha ou prepúcio, geralmente resultado de um orifício prepucial demasiadamente pequeno $[1,3,7]$. A fimose pode ser congênita ou adquirida por trauma, também pode ocorrer secundariamente a neoplasia peniana ou celulite prepucial. A inabilidade de expor o pênis causa irritação prepucial e infecção secundária ao urinar no interior do prepúcio $[1,2,7]$. Não existe qualquer predisposição racial. A fimose congênita é reconhecida em neonatos, mas pode não ser detectada durante alguns meses [7].

Animais afetados tem um orifício prepucial pequeno ou inexistente. A tentativa de exposição manual infrutífera ou a palpação do pênis podem revelar a presença do problema, impedindo o avanço do pênis. A citologia prepucial pode confirmar inflamação ou infecção, sugerindo a realização de cultura bacteriana. $\mathrm{O}$ diagnóstico diferencial inclui a hipoplasia peniana e o hermafroditismo. A fimose causada por doença infecciosa ou inflamatória pode ser aliviada por compressas de água morna, antibioticoterapia e desvio da urina com uso de sonda uretral. O prepúcio pode ser lavado diariamente com solução isotônica para reduzir a irritação pela urina. A fimose causada por anomalia adquirida ou severa é controlada por reconstrução do orifício prepucial $[3,7]$.

O objetivo da cirurgia é aumentar o orifício prepucial maximizando o movimento do pênis dentro e fora do prepúcio [2,7]. As técnicas já existentes mais consagradas consistem no aumento do diâmetro circunferencial do óstio prepucial; e a abertura do orifício prepucial em forma de cunha. Ambas as técnicas apresentam a estenose cicatricial como o maior inconveniente pós-operatório [1-3,7].

\section{RELATO DO CASO}

Foram atendidos no Hospital de Clínicas Veterinárias da Universidade Federal do Rio Grande do Sul (HCV-UFRGS) dois cães com suspeita clínica de fimose. Após o atendimento clínico adequado e a confirmação do diagnóstico, os animais foram encaminhados para a cirurgia de postioplastia, lançando-se mão da adaptação de duas técnicas já consagradas pela literatura, transformadas numa modificada.

Os cães operados eram de raças distintas, sendo um da raça American Staffordshire Terrier e outro sem raça definida (Figuras 1 e 2). Ambos apresentavam fimose congênita e inabilidade de exposição peniana espontânea, assim como retenção urinária e balanopostite.

Os animais foram preparados para o procedimento cirúrgico com tricotomia local e receberam medicação pré-anestésica com acepromazina $\left(0,1 \mathrm{mg} \cdot \mathrm{kg}^{-1}\right)$ e meperidina $\left(3 \mathrm{mg} \cdot \mathrm{kg}^{-1}\right)$. Os pacientes foram posicionados em decúbito dorsal, a porção cranial do prepúcio isolado, o canal uretral sondado e preparado para uma cirurgia asséptica. Realizou-se indução anestésica com propofol $\left(5 \mathrm{mg} \cdot \mathrm{kg}^{-1}\right)$ e no trans-operatório foram mantidos com isofluorano a efeito [6]. Na região cirúrgica foi realizada anti-sepsia com solução de clorexidine $0,2 \%$. Como antibiótico pré-operatório foi utilizado ampicilina (20mg. $\left.\mathrm{kg}^{-1}\right)$ por via intravenosa.

A técnica modificada para correção da fimose consiste em associar as técnicas de incisão em forma de cunha (triangular) na região craniodorsal do prepúcio com a incisão circunferencial completa para um melhor resultado pós-cirúrgico e menor índice dos problemas relacionados com as técnicas anteriores individuais. Realizou-se uma incisão circunferencial com um bisturi em torno do óstio prepucial e completou-se a excisão da mucosa com uma tesoura de Metzenbaum. Ampliou-se a incisão com o bisturi na região craniodorsal do prepúcio em formato triangular (cunha) de aproximadamente 5mm (Figura 3). Completou-se a excisão do tecido mucocutâneo em formato de cunha e retirou-se o excedente. Elaborou-se pontos de reparo entre as regiões da mucosa e da pele para facilitar a posterior união desses tecidos. Removido o tecido, iniciou-se a sutura da mucosa diretamente na pele adjacente. A sutura foi realizada com padrão de pontos simples interrompidos e utilizou-se fio não absorvível (mononylon) 4-0 (Figura 4).

Terminado o procedimento cirúrgico, lavou-se novamente a região prepucial com solução isotônica de cloreto de sódio e clorexidine $0,2 \%$. Foi indicado como tratamento pós-operatório, limpeza com solução anti-séptica três vezes ao dia, manutenção do animal em local limpo e uso de colar Elizabetano. Foram removidos os pontos de sutura cutânea em 10 dias, sendo observado nesse período a capacidade de exposição peniana e infecção local. A recuperação foi efetiva, sendo utilizado no período pós-operatório cetoprofeno $\left(2 \mathrm{mg} \cdot \mathrm{kg}^{-1}\right)$ e cloridrato de tramadol $(1 \mathrm{mg} / \mathrm{kg})$ durante 2 dias como antinflamatório e analgésico, assim como enrofloxacina (5mg. $\mathrm{kg}^{-1}$ ) como antibiótico. $\mathrm{O}$ animal apresenta, desde então, facilidade de micção e exposição do pênis. 


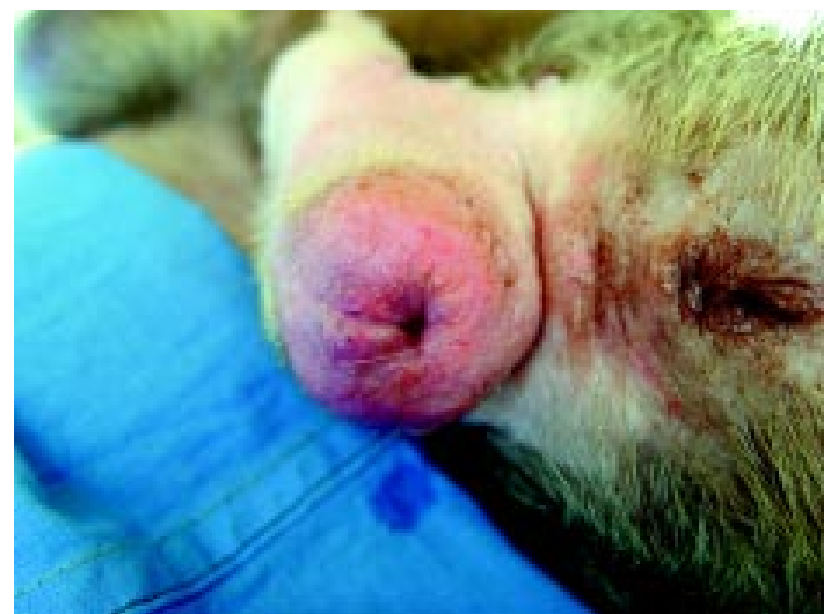

Figura 1. Fimose em canino American Staffordshire.

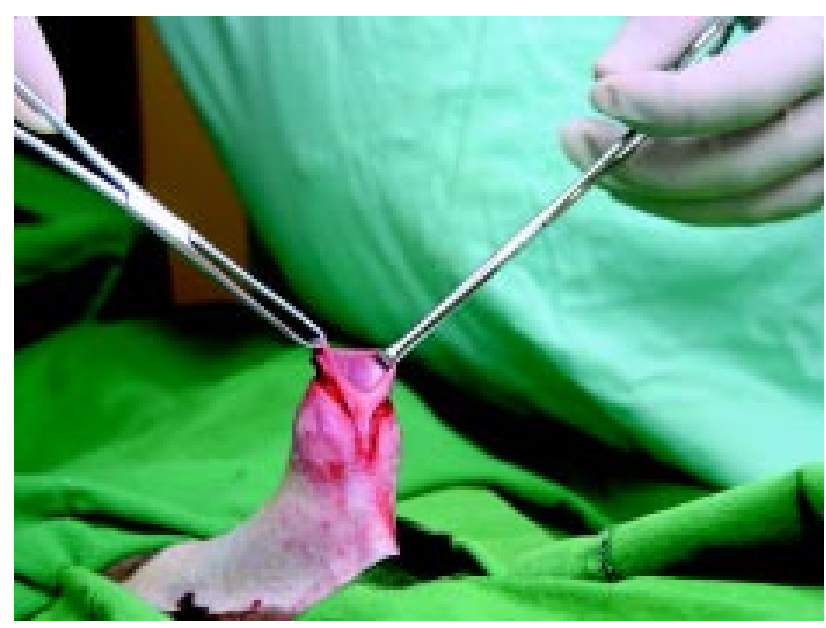

Figura 3. Local de incisão da postioplastia modificada.

\section{DISCUSSÃO}

A fimose pode ser persistente se a incisão não for suficiente. Uma exposição persistente da glande pode ocorrer se o prepúcio ventrocaudal for incisado. Sem cirurgia, uma balanopostite severa poderá ocorrer causando desconforto. Um segundo procedimento cirúrgico pode ser necessário depois que animal estiver em idade madura [1,7]. O prognóstico da fimose congênita é geralmente favorável, podendo haver necessidade de outra intervenção cirúrgica para maior ampliação do orifício prepucial, depois do total crescimento do paciente [7].

A fimose é mais comum em pacientes humanos do que em cães [9]. Sendo que em humanos a técnica de circuncisão é amplamente realizada tanto na infância, geralmente em idade pediátrica, para correção do orifício prepucial, quanto na idade adulta para

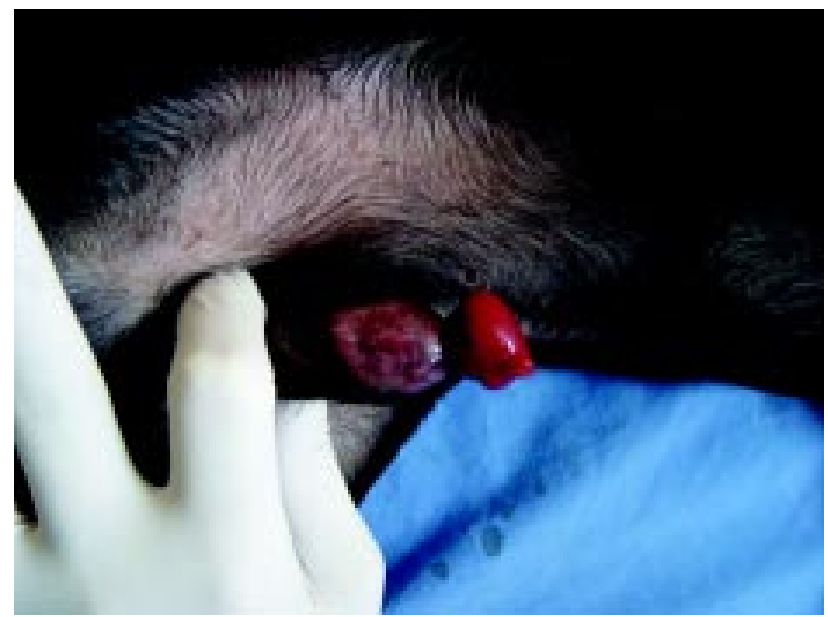

Figura 2. Fimose em canino S.R.D.

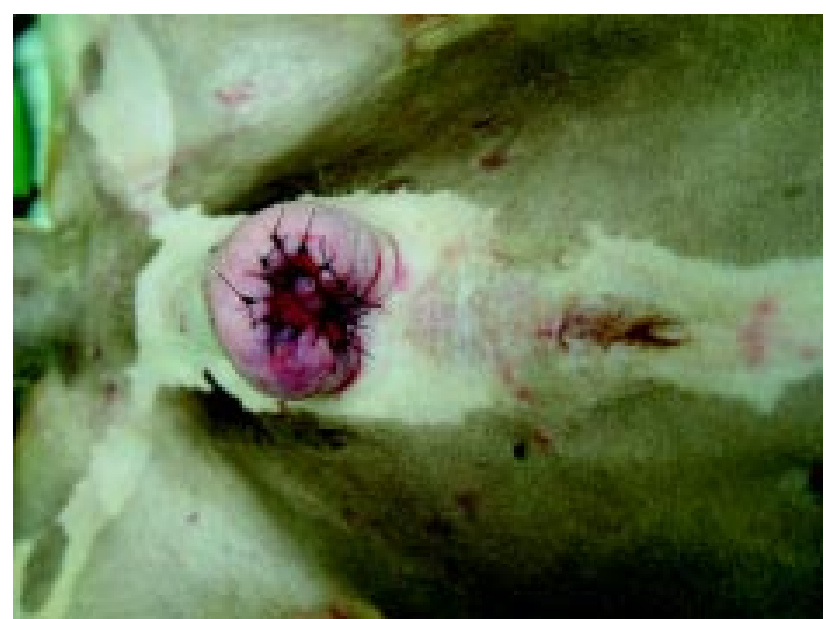

Figura 4. Resultado imediato após sutura com pontos simples iso.

prevenção de infecções e de outros problemas [5]. Em felinos a fimose é ainda mais improvável do que em cães. Quando acontecem, geralmente são de natureza congênita e necessitam correção cirúrgica para evitar problemas futuros, principalmente balanopostite. A técnica cirúrgica utilizada em felinos é geralmente a retirada de uma porção do prepúcio em sua região dorsal em forma de cunha [4]. Ainda há casos reportados em equiinos, sendo esses também incomuns de acontecerem, mas facilmente corrigidos com cirurgia [8].

A postioplastia modificada mostrou ser mais eficaz que a simples circuncisão do óstio prepucial ou a retirada de um fragmento em forma de cunha de forma isolada, principalmente no que diz respeito à estenose cicatricial, que é o maior inconveniente pósoperatório. Sabe-se que os cães são os mais afetados e que a observação do problema, pelo proprietário, o mais cedo possível é fundamental para que a infecção 
e inflamação local não se agravem, assim como o atendimento veterinário qualificado para diagnosticar o problema e a habilidade e experiência do cirurgião, retirando apenas a porção necessária do prepúcio.

A escolha do clorexidine como anti-séptico tanto no período pré como no pós-operatório deu-se devido ao fato de ele causar menos reação cutânea local que o álcool, iodo ou a associação de ambos. Do mesmo modo, o fio de sutura escolhido (mononylon) demonstrou ser totalmente inerte na região mucocutânea [2,3], apesar de outros autores indicarem realizar a sutura com fio absorvível [7].

O protocolo anestésico escolhido proporcionou boa sedação e analgesia aos pacientes nos períodos pré, trans e pós-operatório, sem qualquer alteração ou reação a qualquer uma das medicações. O analgésico e antinflamatório administrados aos pacientes nos dias subseqüentes à cirurgia também proporcionaram completo conforto aos pacientes, assim como a escolha da enrofloxacina como antibiótico pós-cirúrgico.

Os resultados da postioplastia modificada para a correção de fimose em cães mostraram-se amplamente satisfatórias. Além de não aumentar o tempo cirúrgico de forma considerável, diminui muito o índice de problemas pós-operatórios e praticamente exclui a necessidade de nova intervenção cirúrgica. Há alivio e resultados imediatos ao animal, devolvendo-lhe a plena capacidade de exposição peniana e micção, assim como a diminuição da possibilidade de infecção local.

\section{REFERÊNCIAS}

1 Bojrab M.J. 1996. Técnicas atuais em cirurgia de pequenos animais. 3.ed. São Paulo: Roca, pp. 401-402.

2 Boothe H.W.1998. Pênis, prepúcio e escroto. In: Slatter, D (Ed). Manual de cirurgia de pequenos animais. 2.ed. São Paulo: Manole, pp. 1593-1606.

3 Boothe H.W. 1998. Cirurgia peniana e prepucial. In: Bichard S.J. \& Scherding R.G. Manual Saunders: Clinica de pequenos animais. São Paulo: Roca, pp. 998-1001.

4 Bright S.R. \& Mellanby R.J. 2004. Congenital phimosis in a cat. Journal of feline medical surgery. 6: 367-370.

5 Dossanti A., Ginesu G., Ianiccelli M. \& Balata A. 2005. Phimosis. Preputial plasty using transversal side with EMLA local anestesic cream. Journal of pediatric surgery. 40: 713-715.

6 Fantoni D.T. \& Cortopassi S.R.G. 2002. Anestesia em cães e gatos. São Paulo: Roca, pp. 215-221.

7 Fossum T.W. 2002. Small animal surgery. 2nd ed. Missouri: Mosby, pp. 567-572.

8 Ndiritu C.G. 1979. Lesions of th canine penis and prepuce. Modern veterinary practice. 60: 712-715.

9 Schumacher J. \& Vaunghan J.T. 1998. Surgery of the penis and prepuce. Veterinary clinical of North American equine practice. 4: 473-491. 